\title{
Development of an Area-selective Technique for Electrochemical Hydrogen Detection with Laser Local Activation
}

\author{
Masatoshi SAKAIRI, ${ }^{1) *}$ Koya IGARASHI ${ }^{2)}$ and Akihide NAGAO ${ }^{3,4)}$ \\ 1) Faculty of Engineering, Hokkaido University, Kita-13, Nishi-8, Kita-ku, Sapporo, 060-8628 Japan. \\ 2) Graduate School \\ of Engineering, Hokkaido University, Kita-13, Nishi-8, Kita-ku, Sapporo, 060-8628 Japan. \\ 3) Material Surface \& Interface \\ Science Research Department, Steel Research Laboratory, JFE Steel Corporation, 1-1 Minamiwatarida-cho, Kawasaki-ku, \\ Kawasaki, Kanagawa, 210-0855 Japan. \\ 4) International Institute for Carbon-Neutral Energy Research (WPI-I2CNER), \\ Kyushu University, 744 Motooka, Nishi-ku, Fukuoka, Fukuoka, 819-0395 Japan.
}

(Received on June 1, 2015; accepted on July 28, 2015)

\begin{abstract}
An area-selective technique for electrochemical hydrogen detection with laser local activation (focused pulse YAG laser irradiation) has been newly developed. The developed technique was applied to measure hydrogen permeation behavior of iron at selected areas of various grain structures. The hydrogen permeation current was detected after the laser irradiation, suggesting that indirect activations of hydrogen generation and entry reactions were produced by the focused pulse YAG laser irradiation, which activated dissolution of metals at the irradiated areas. An obtained hydrogen diffusion coefficient, $D_{H}$, was in good agreement with previously reported $D_{H}$ of iron, while a clear dependence of $D_{H}$ on grain structure at the entry side was not found.
\end{abstract}

KEY WORDS: hydrogen; diffusion coefficient; laser local activation; grain structure.

\section{Introduction}

With the recent demands for reducing energy and resource in construction industry and automobiles, production of high strength steels is increasing. It is, however, well known that increasing strength of steels generally leads to higher susceptibility to hydrogen embrittlement. ${ }^{1,2)}$ A reduction in susceptibility to hydrogen embrittlement of high strength steels has become an important issue to ensure reliability and safety in the practical use of steels. Hydrogen embrittlement has, therefore, attracted much attention recently. ${ }^{3-14)}$

Several techniques such as thermal desorption spectroscopy, ${ }^{15)}$ hydrogen microprint technique, ${ }^{16)}$ silver decoration method, ${ }^{17)}$ electrochemical hydrogen detection, ${ }^{18,19)}$ and tritium autoradiography ${ }^{20}$ ) have been applied to measure or visualize hydrogen in the metals. The hydrogen entry efficiency (ratio of hydrogen permeation current and hydrogen generation current) and hydrogen diffusion coefficient, $D_{\mathrm{H}}$, may depend on grain boundary and segregation at the entry surface. However, these effects on hydrogen permeation behavior are not fully understood mainly due to the difficulty of the control of the entry area of hydrogen. To reveal these effects on hydrogen permeation behavior, an area-selective hydrogen detection technique was newly developed in the current study.

A focused pulse YAG laser irradiation can activate anodic reaction at the irradiated area. ${ }^{21,22)}$ In the case of immersion corrosion of iron, the activation of anodic reaction

* Corresponding author: E-mail: msakairi@eng.hokudai.ac.jp DOI: http://dx.doi.org/10.2355/isijinternational.ISIJINT-2015-304
$\left(\mathrm{Fe} \rightarrow \mathrm{Fe}^{2+}+2 \mathrm{e}^{-}\right)$may lead to an increase in cathodic reaction such as hydrogen generation reaction around the area. Figure 1 shows a schematic representative of the indirect activations of hydrogen generation and entry reaction by the focused pulse YAG laser irradiation (laser local activation). In the figure, $\mathrm{H}_{\mathrm{ad}}$ and $\mathrm{H}_{\mathrm{ab}}$ indicate adsorbed and absorbed hydrogen, respectively, and Volmer $\left(\mathrm{H}_{2} \mathrm{O}+\mathrm{e}^{-} \rightleftarrows \mathrm{Had}+\mathrm{OH}^{-}\right.$; neutral and alkaline solutions), Tafel $\left(\mathrm{H}_{\mathrm{ad}}+\mathrm{H}_{\mathrm{ad}} \rightleftarrows \mathrm{H}_{2}\right)$ and Herovsky $\left(\mathrm{H}_{\mathrm{ad}}+\mathrm{H}_{3} \mathrm{O}^{+}+\mathrm{e}^{-} \rightleftarrows \mathrm{H}_{2}+\mathrm{H}_{2} \mathrm{O}\right)$ are $\mathrm{H}_{\mathrm{ad}}$ and $\mathrm{H}_{2}$ generation reactions. Combination of the laser local activation and

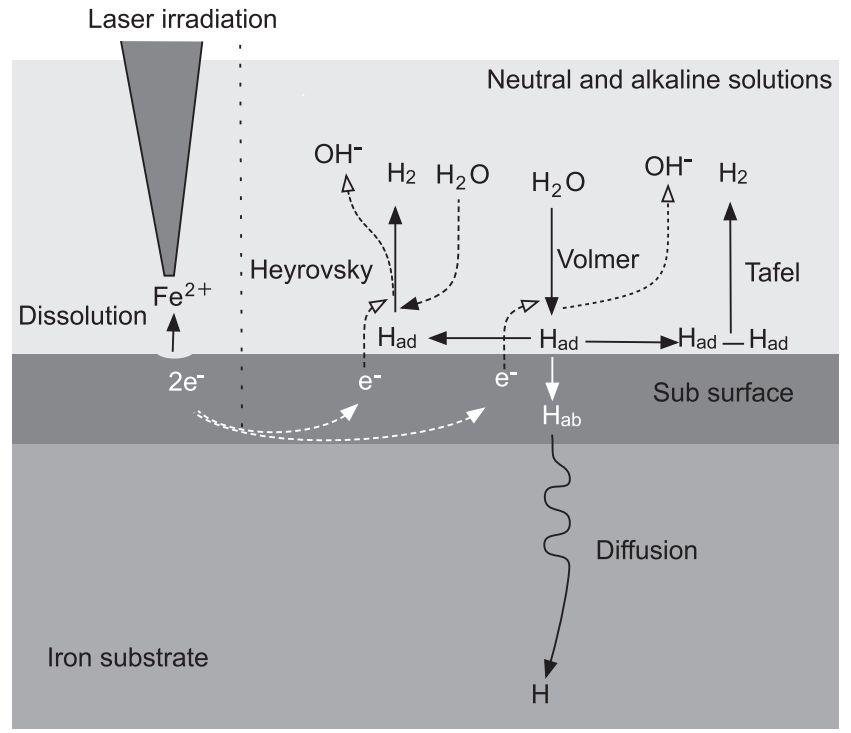

Fig. 1. Schematic representative of indirect activations of hydrogen generation reaction by irradiation of laser. 
electrochemical cell for hydrogen detection enables investigation of hydrogen permeation behavior at a selected area.

The purpose of this study is to develop the area-selective technique for electrochemical hydrogen detection with laser local activation. This newly developed technique was applied to measure hydrogen permeation behavior of iron at selected areas of various grain structures.

\section{Experimental}

\subsection{Specimen}

A $1.0 \mathrm{~mm}$-thickness plate-type specimen was machined from an iron sheet. The chemical composition of the investigated iron is shown in Table 1. One side of the specimen for the hydrogen detection was mechanically ground under running water with $\mathrm{SiC}$ paper up to $\# 1500$, and then nickel was plated electrochemically in $0.312 \mathrm{kmol} \mathrm{m}^{-3} \mathrm{NiSO}_{4} /$ $0.781 \mathrm{kmol} \mathrm{m}^{-3} \mathrm{H}_{3} \mathrm{BO}_{3}$ solution at $4 \mathrm{~mA} \mathrm{~cm}^{-2}$ for $720 \mathrm{~s}$. After nickel deposition, hydrogen entry (laser local activation) side of the specimen was mechanically ground under running water by $\mathrm{SiC}$ paper up to $\# 4000$ and then polished with colloidal silica.

\subsection{Detection of Permeated Hydrogen after Laser Local Activation}

A schematic drawing of cross section of cell unit (corrosion cell, specimen, and hydrogen detection cell) for electrochemical detection of permeated hydrogen with laser local activation is presented in Fig. 2. A specimen was placed between the corrosion cell (hydrogen entry side) and the hydrogen detection cell. The hydrogen detection side (nickel plated side) of the specimen was attached on the hydrogen

Table 1. Chemical composition of investigated iron (mass $\%$ ).

\begin{tabular}{cccccccc}
\hline C & Si & Mn & P & S & Al & N & Fe \\
\hline 0.001 & 0.01 & 0.01 & 0.001 & 0.0006 & 0.002 & 0.0023 & bal. \\
\hline
\end{tabular}

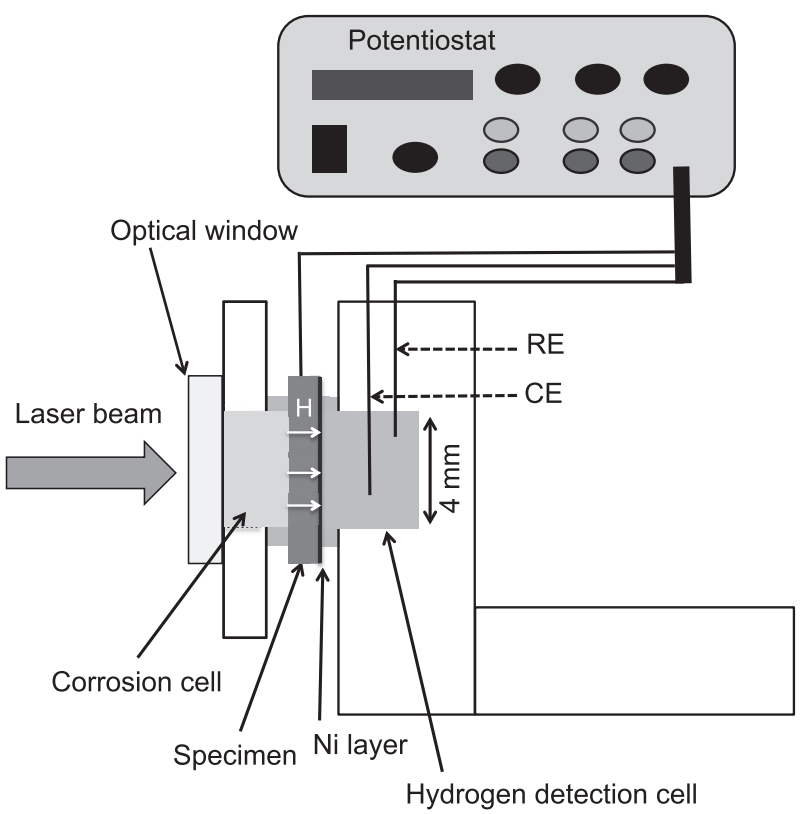

Fig. 2. Schematic drawing of cell unit (corrosion cell, specimen, and hydrogen detection cell) for electrochemical hydrogen detection cell with a corrosion cell. detection cell and the hydrogen entry side (laser local activation side) was attached on the corrosion cell, and then 0.2 $\mathrm{cm}^{3}$ of $1 \mathrm{kmol} \mathrm{m}^{-3} \mathrm{NaOH}$ solution was introduced to the hydrogen detection cell. Pt wires were used as counter electrode, $\mathrm{CE}$, and reference electrodes, RE, for the hydrogen detection cell. To measure permeated hydrogen through the specimen electrochemically, the specimen was polarized at $-30 \mathrm{mV}$ vs. Pt. After the current of hydrogen detection cell reached sufficiently low and steady value (it took about 72 ks after the potential was applied), the corrosion cell (the left side of the specimen in Fig. 2) was filled with $0.1 \mathrm{kmol} \mathrm{m}^{-3}$ $\mathrm{NaCl}$ solution. A schematic drawing of the experimental system for detection of permeated hydrogen with laser local activation is shown in Fig. 3. The cell unit was placed on $\mathrm{XYZ}$ stage, and the specimen was irradiated with a focused Nd-YAG laser (wave length $532 \mathrm{~nm}$, pulse frequency 10 $\mathrm{s}^{-1}$, pulse duration $8 \mathrm{~ns}$, and power $20 \mathrm{~mW}$ at the front of the lens) for $10 \mathrm{~s}$ at several selected areas. The hydrogen permeation current was continuously recorded after the corrosion cell was filled with the $\mathrm{NaCl}$ solution.

\subsection{Surface Observation}

The surface morphology of the polished specimen before and after the tests was observed by scanning electron microscopy, SEM. Prior to the surface observation, the specimen was chemically etched with $3 \%$ nital solution for $5 \mathrm{~s}$, then rinsed well with highly purified water and dried under air stream. An inverse pole figure (IPF) map of the specimen was also taken by electron backscatter diffraction, EBSD.

\section{Results and Discussion}

Figure 4 shows a typical example of SEM (back scattered electron) surface image of the specimen. The grains with an average size of $500 \mu \mathrm{m}$ are clearly observed in the figure. From the IPF map, the observed grains in Fig. 4 were assigned to each of (111), (103), (112), and (113).

Figure 5 shows SEM (back scattered electron) surface image (a) before and (b) after the tests, and (c) IPF map corresponding to Fig. 5(b). In the figure (b) and (c), the circles and " $\mathrm{P}-\mathrm{x}$ " indicate the irradiated area; the horizontal white

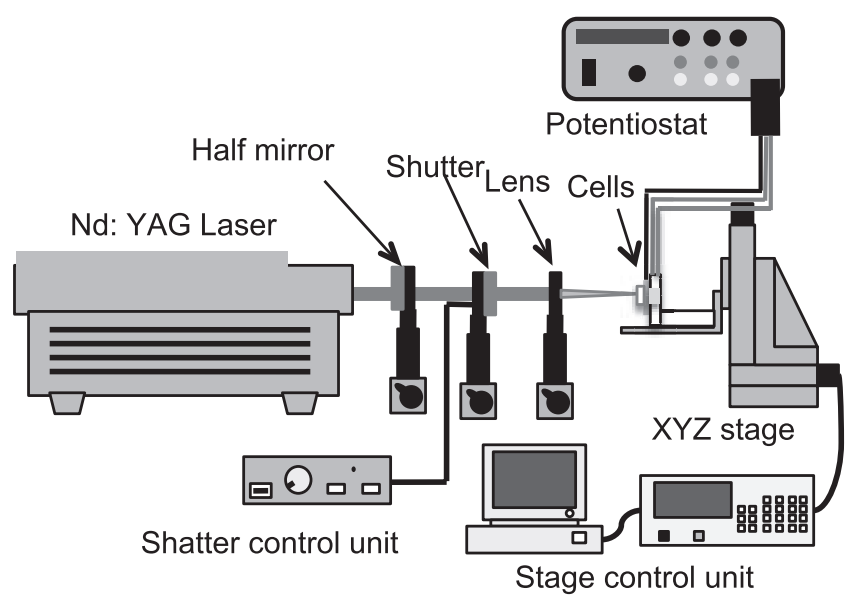

Fig. 3. Schematic drawing of experimental system for detection of permeated hydrogen with laser local activation. 
line close to P-1 in the figure was accidentally introduced during a sample preparation prior to the SEM observation. A clear difference is not found in the specimen surface between (a) and (b), which indicates that severe corrosion did not occur during the test and the dissolution reaction occurred mainly at the laser irradiated areas. From Fig. 5(b), it is noticed that laser irradiated different grain areas.

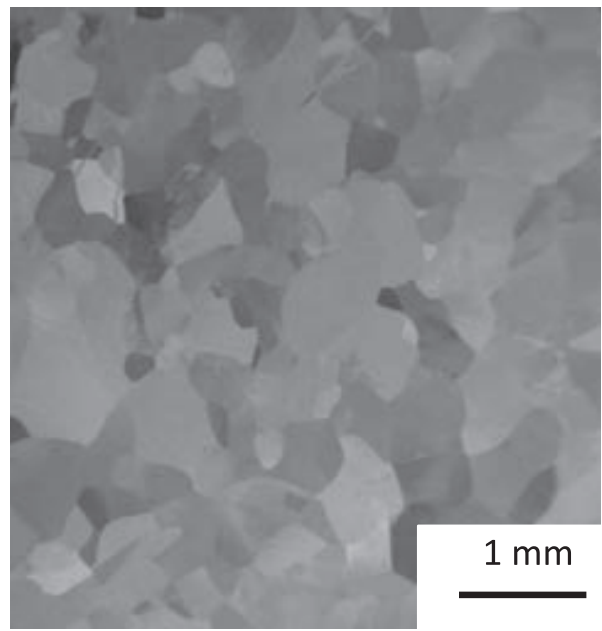

Fig. 4. SEM (back scattered electron) surface image of the specimen
From Fig. 5(c), P-1 is triple point of (111), (112), (113) grains, P-2 is triple point of (112), (113), (213) grains, P-3 is inside (103) grain, and P-4 is inside (112) grain. However, it should be noted that the size of the irradiated area is different between these four areas due to an insufficient control of laser irradiation. The laser local activation with size-controlled would be essential to investigate hydrogen generation rate or hydrogen entry efficiency at a selected area. To achieve this, further improvement and optimization of the technique will be required.

The hydrogen permeation currents were measured at the four different areas shown in Fig. 5. Figure 6 shows changes in hydrogen permeation current, (a) total duration of the experiment and (b) expansion of P-3 shown in Fig. 6 (a), after the laser irradiation. The arrows in the figure indicate times when the laser was irradiated. Changes of the hydrogen permeation currents are observed after the laser irradiation. Independent of the areas, the hydrogen permeation current increases suddenly after a certain time of laser irradiation, reaches a maximum value, and then decreases. It finally returns to almost the same value before the laser irradiation. The results shown here indicate that indirect activations of hydrogen generation and entry reactions were produced by the laser local activation.

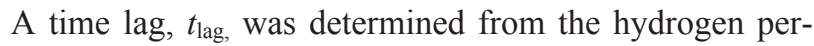
meation current as presented in Fig. 7, which enlarges the
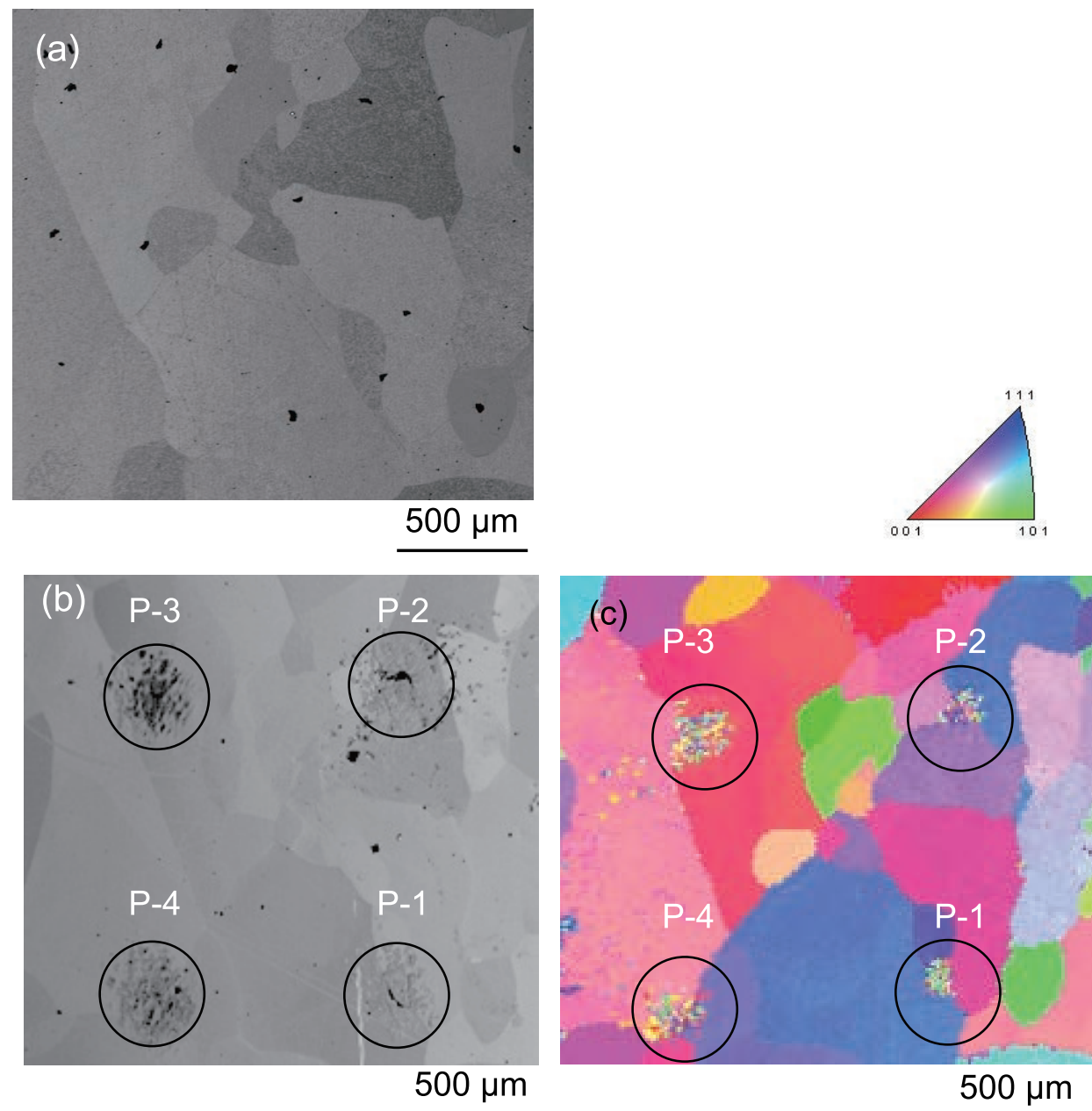

Fig. 5. SEM (back scattered electron) surface image (a) before and (b) after the tests, and (c) IPF map corresponding to Fig. 5(b). (Online version in color.) 
(a)
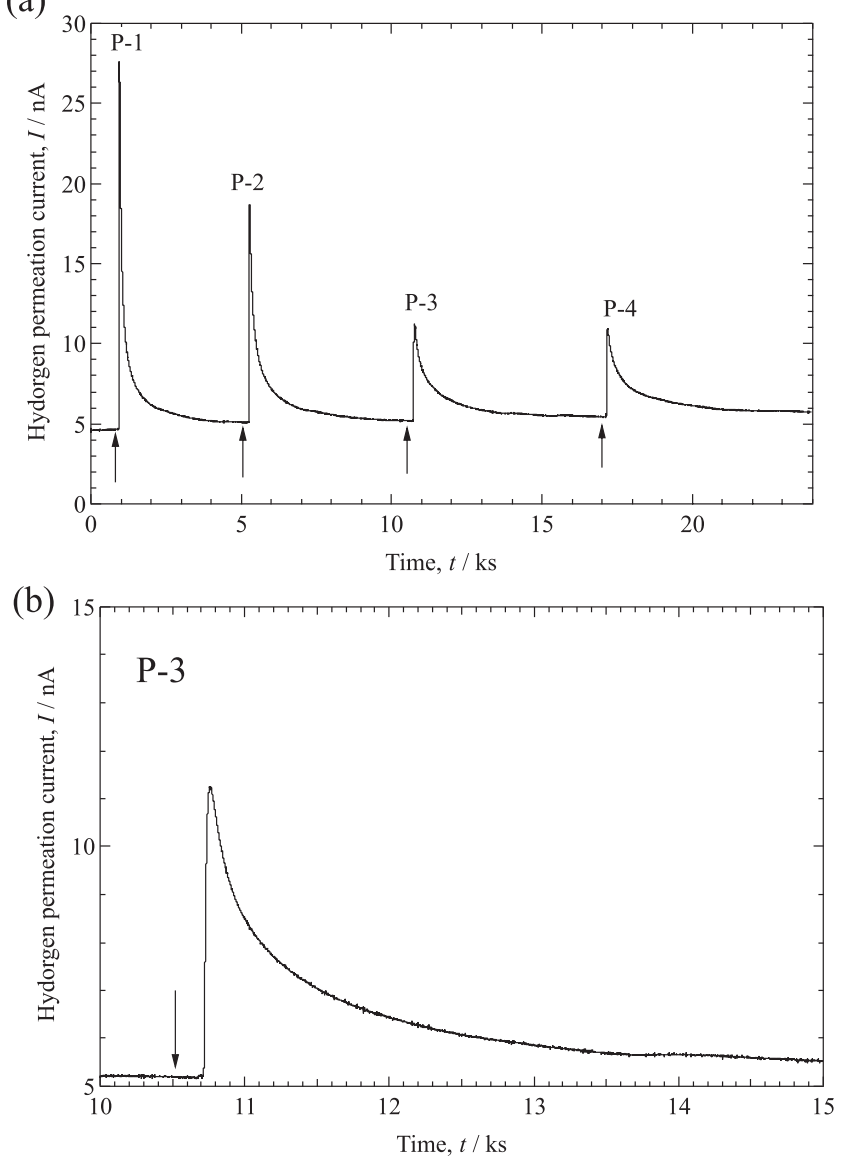

Fig. 6. Changes in hydrogen permeation current, (a) total duration of the experiment and (b) expansion of P-3 in (a) after the laser irradiation at different areas shown in Fig. 5.

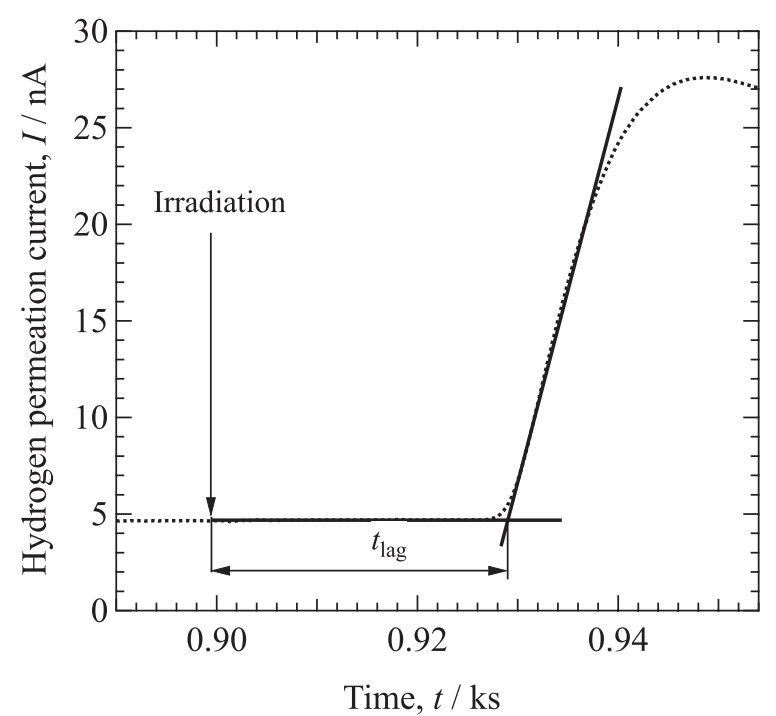

Fig. 7. Determination method of $t_{\text {lag }}$ from detected hydrogen permeation current.

hydrogen permeation current of P-1 shown in Fig. 6(a). At approximately $250 \mathrm{~s}$ after the irradiation, the hydrogen permeation current starts to increase, and a plateau region is observed before the decrease of the current. This result suggests that constant concentration of $\mathrm{H}_{\mathrm{ad}}$ at the entry side was achieved during laser irradiation. Several methods have been proposed to determine $D_{\mathrm{H}}{ }^{23,24)}$ from hydrogen permeation data. In the present study, the time lag method, $t_{\text {lag }}=L^{2} /\left(2 D_{\mathrm{H}}\right)$, was used to calculate $D_{\mathrm{H}}$ from the results shown in Fig. 6. In the equation, $L$ is the thickness of the specimen. The difference of $D_{\mathrm{H}}$ was subtle among the four laser irradiated areas shown in Fig. 5 and the average $D_{\mathrm{H}}$ of the specimen was about $4.2 \times 10^{-9} \mathrm{~m}^{2} \mathrm{~s}^{-1}$; this value is in good agreement with previously reported $D_{\mathrm{H}}$ of iron. ${ }^{25)}$ With improving the accuracy of the irradiation position and size, this technique has a potential to visualize preferential entry sites for hydrogen in a relationship with grain structure such as a specific grain boundary or a particular grain orientation.

\section{Conclusion}

A combined technique of electrochemical cell with laser local activation for hydrogen detection was newly developed, and it was applied to measure hydrogen permeation behavior of iron at different grain structures. The increase of hydrogen permeation current was observed after the laser irradiation, suggesting that indirect activations of hydrogen generation and entry reactions were produced by a focused pulse YAG laser irradiation. The measured hydrogen permeation current makes it possible to calculate hydrogen diffusion coefficient. A clear dependence of hydrogen diffusion coefficient on grain structure was not found for iron.

\section{REFERENCES}

1) Y. Mukai: Kobe Steel Eng. Rep., 55 (2005), 30.

2) S. Matsuyama: Delayed Fracture, Nikkan Kyogyo Shimbun, LTD., Tokyo, (1989), (in Japanese).

3) T. Michler, Y. Lee, R. P. Gangloff and J. Naumann: Int. J. Hydrogen Energ., 34 (2009), 3201.

4) K. Ebihara, T. Iwamoto, Y. Matsubara, H. Yamada, T. Okamura, W. Urushihara and T. Omura: ISIJ Int., 54 (2014), 153.

5) H. Hatano, M. Fujinami, K. Arai, H. Fujii and M. Nagumo: Acta Mater., 67 (2014), 342.

6) M. Koyama, H. Springer, S. V. Merzlikin, K. Tsuzaki, E. Akiyama and D. Rabbe: Int. J. Hydrogen Energ., 39 (2014), 4634.

7) A. Nagao, C. D. Smith, M. Dadfarnia, P. Sofronis and I. M. Robertson: Procedia Mater. Sci., 3 (2014), 1700.

8) T. Matsuno, Y. Sekito, E. Sakurada, T. Suzuki, K. Kawasaki and M. Suehiro: ISIJ Int., 54 (2014), 2369.

9) A. Nagao, M. L. Martin, M. Dadfarnia, P. Sofronis and I. M. Robertson: Acta Mater., 74 (2014), 244.

10) D. Hirakami, T. Manabe, K. Ushioda, K. Noguchi, K. Takai, Y. Hata, S. Hata and H. Nakashima: Tetsu-to-Hagané, 101 (2015), 59.

11) T. Michler, J. Naumann, M. Hock, K. Berreth, M. P. Balogh and E. Sattler: Mater. Sci. Eng. A, 628 (2015), 252.

12) I. Park, S. Lee, H. Jeon and Y. Lee: Corros. Sci., 93 (2015), 63.

13) P. R. Sere, M. Zapponi, C. I. Elsner and A. R. Di Sali: Corros. Sci., 40 (1998), 1711.

14) T. Kushida: ISIJ Int., 43 (2003), 470.

15) K. Takai: Zairyo-to-Kankyo, 60 (2011), 230 (in Japanese).

16) A. Nagao, K. Hayashi, K. Oi and S. Mitao: ISIJ Int., 52 (2012), 213.

17) E. Akiyama and S. Matsuoka: J. Jpn Inst. Met., 77 (2013), 622 (in Japanese).

18) M. A. V. Devanathan and Z. Stachurski: J. Electrochem. Soc., 111 (1964), 619.

19) J. McBreen, L. Nanis and W. Beck: J. Eloctrochem. Soc., 113 (1966), 1218.

20) H. Okada, G. Itho and M. Kanno: J. Jpn. Inst. Light Met., 42 (1992), 112 .

21) K. Yanada, M. Sakairi1, T. Kikuchi1, Y. Oya and Y. Kojima: Surf. Interface Anal., 42 (2010), 189.

22) M. Sakairi, M. Kinjyo and T. Kikuchi: Electrochim. Acta, 56 (2011), 1786.

$23)$ T. Tsuru: Zairyo-to-Kankyo, 63 (2014), 3 (in Japanese).

24) M. Sakairi: Electrochemistry, in press (in Japanese).

25) T. Kushida: Zairyo-to-Kankyo, 49 (2000), 195 (in Japanese). 